\title{
Sphingolipid and Ceramide Homeostasis: Potential Therapeutic Targets
}

\author{
Simon A. Young, ${ }^{1}$ John G. Mina, ${ }^{2}$ Paul W. Denny, ${ }^{2,3}$ and Terry K. Smith ${ }^{1}$ \\ ${ }^{1}$ School of Biology and Chemistry, Biomedical Sciences Research Complex, University of St Andrews, \\ North Haugh, KY16 9ST, UK \\ ${ }^{2}$ Biophysical Sciences Institute, School of Biological and Biomedical Sciences and Department of Chemistry, \\ University of Durham University Science Laboratories, South Road, Durham DH1 3LE, UK \\ ${ }^{3}$ School of Medicine and Health, Durham University, Queen's Campus, Stockton-on-Tees TS17 6BH, UK
}

Correspondence should be addressed to Paul W. Denny, p.w.denny@durham.ac.uk and Terry K. Smith, tks1@st-andrews.ac.uk

Received 31 July 2011; Accepted 20 October 2011

Academic Editor: Todd B. Reynolds

Copyright () 2012 Simon A. Young et al. This is an open access article distributed under the Creative Commons Attribution License, which permits unrestricted use, distribution, and reproduction in any medium, provided the original work is properly cited.

\begin{abstract}
Sphingolipids are ubiquitous in eukaryotic cells where they have been attributed a plethora of functions from the formation of structural domains to polarized cellular trafficking and signal transduction. Recent research has identified and characterised many of the key enzymes involved in sphingolipid metabolism and this has led to a heightened interest in the possibility of targeting these processes for therapies against cancers, Alzheimer's disease, and numerous important human pathogens. In this paper we outline the major pathways in eukaryotic sphingolipid metabolism and discuss these in relation to disease and therapy for both chronic and infectious conditions.
\end{abstract}

\section{Introduction}

Sphingolipids are a class of natural products that were first characterised by the German-born chemist and clinician Johann L. W. Thudichum in 1884. They consist of an sphingoid base backbone, for example sphingosine, that can be $\mathrm{N}$ acylated with fatty acids forming ceramides. To these lipid anchors is attached a variety of charged, neutral, phosphorylated and/or glycosylated moieties forming complex sphingolipids, for example phosphorylcholine to make the most abundant mammalian sphingolipid, sphingomyelin. These moieties result in both polar and nonpolar regions giving the molecules an amphipathic character which accounts for their tendency to aggregate into membranous structures. Furthermore, the divergence encountered in their chemical structures allows them to play distinctive roles within cellular metabolism (Figure 1) $[1,2]$.

Sphingolipids are ubiquitous and essential structural components of eukaryotic membranes [3] as well as some prokaryotic organisms and viruses [2]. They are found predominantly in the outer leaflet of the plasma membrane [4], the lumen of intracellular organelles [5], and lipoproteins [2]. Sphingolipids (most notably ceramide) are also bioactive signalling molecules that control a plethora of cellular events including signal transduction, cell growth, differentiation, and apoptosis [6-10]. In addition, their role in protein kinase $\mathrm{C}$ regulation has more recently been elucidated [11]. It is noteworthy that some sphingolipid metabolites can exhibit both structural and signalling functionalities. For example, glycosphingolipids have been reported to be involved in cellular recognition complexes, for example, blood group antigens, cell adhesion, and the regulation of cell growth [4].

Over the last decade, there has been an exponential increase in the study of sphingolipids. However, the investigation and deciphering of the functions of each specific sphingolipid remains challenging due to the complexity in sphingolipid metabolic interconnection, their varied biophysical properties (neutral or charged), the hydrophobic nature of the enzymes involved, and the presence of multiple pathways that can operate in parallel [12]. The interaction of sphingolipid biosynthesis with other cellular metabolic pathways, for example glycerolipid metabolism, introduces another 


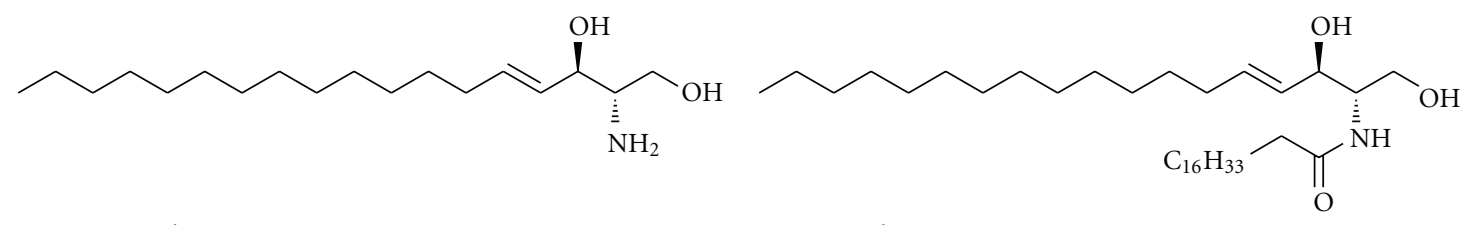

Sphingosine

Ceramide

(a)

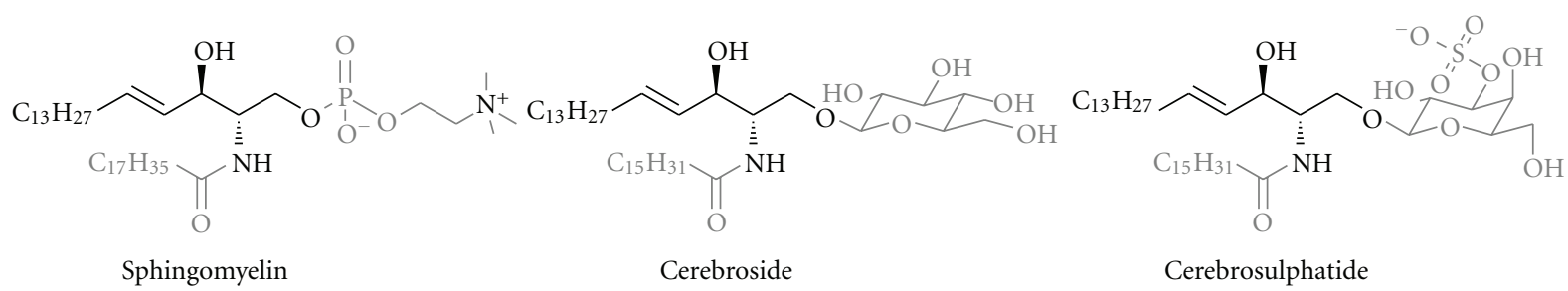

(b)

FIgURE 1: (a) The chemical structures of sphingosine and $\mathrm{C}_{18}$-ceramide; (b) the lipids isolated by Thudichum.

layer of complexity and the cellular role of an individual sphingolipid could be defined as a multidimensional in terms of subcellular localisation, regulation and mechanism of ac$\operatorname{tion}(\mathrm{s})[12]$.

Whilst the scientific literature has been enriched by articles focused on structural diversity [13-18] and cellular metabolism $[2,8-10,12,19-21]$, this paper focuses on the key enzymes involved in the regulation of ceramide, a central sphingolipid and a key bioactive molecule [12]. To this end we discuss the roles of these enzymes in the regulation of biosynthesis, and in the recycling, salvage, and degradation of complex sphingolipids, in mammalian, fungal and protozoan systems. In addition, we relate these observations to disease and potential therapies.

\section{Sphingolipid Metabolism}

Sphingolipid metabolism is a critical cell process [22] constituting a highly complex network of interconnected pathways, with ceramide (and to a lesser degree dihydroceramide) occupying a central position in both biosynthesis and catabolism. Therefore, this simple but highly bioactive sphingolipid represents a metabolic hub [12]. In terms of ceramide, the routes of formation can be grouped into either de novo synthesis; or recycling, salvage, and degradation (Figure 2). Sphingolipid metabolism has been extensively studied in mammalian and fungal systems, where many of the enzymes involved have been identified and characterised. Consequently, the mammalian pathways will be used as the reference model in the following discussion.

2.1. De Novo Synthesis. The first step in the de novo biosynthesis of sphingolipids is the condensation of serine and palmitoyl CoA, a reaction catalysed by the normally rate-limiting serine palmitoyltransferase (SPT, EC 2.3.1.50) to produce 3-ketodihydrosphingosine [23]. SPTs are members of the pyridoxal 5'-phosphate-dependent $\alpha$-oxoamine synthase family who share a conserved motif
(T[FL][GTS]K[SAG][FLV]G) around the PLP-binding lysine (in bold). The mammalian SPTs [23] (and those of other eukaryotes $[24,25])$ are membrane bound in the endoplasmic reticulum as a heterodimer of subunits LCB1 and LCB2 ( $\sim 53$ and $\sim 63 \mathrm{kDa})$; these are both type I integral membrane proteins sharing $\sim 20 \%$ identity. The bacterial SPT is $\sim 30 \%$ identical to both mammalian LCB1 and LCB2 at the amino acid level and has the conserved lysine residue in the PLPbinding motif, however the soluble $45 \mathrm{kDa}$ protein forms active homodimers [26]. Palmitoyl-CoA functions as the best substrate of mammalian SPT in vitro, while it is also the dominant acyl-CoA in vivo, and thus the sphingoid bases from mammalian cells are predominantly C16 [23]. In contrast, the enzyme from the bacteria Sphingomonas wittichii utilises stearoyl-CoA most efficiently [27]. A third subunit increasing enzyme activity has been identified in Saccharomyces cerevisiae [28] and more recently 2 nonhomologous but functionally related proteins have been characterised in a mammalian system [29]. Furthermore, these additional subunits confer distinct acyl-CoA substrate specificities to the mammalian SPT thus explaining the diversity of long chain bases found in mammals [30]. As the "gatekeeper" of sphingolipid biosynthesis, loss of SPT has a catastrophic effect on mammalian cell viability with a partial loss of SPT function seen in the inherited progressive disorder, Hereditary Sensory Neuropathy type I (HSN1) [23]. The molecular basis of this condition is discussed later in this paper.

Following sphinganine (dihydrosphingosine) formation, metabolic differences are encountered. Whilst in fungi and higher plants sphinganine is hydroxylated to phytosphingosine then acylated to produce phytoceramide, in animal cells sphinganine is acylated to dihydroceramide which is later desaturated to form ceramide [31]. Ceramide (or phytoceramide), a central sphingolipid, is then transported from the ER to the Golgi apparatus where further synthesis of complex sphingolipids takes place $[7,19,20,32]$. Ceramide can be phosphorylated by ceramide kinase [33], glycosylated by glucosyl or galactosyl ceramide synthases [34], or acquire a variety of neutral or charged head groups to form various 


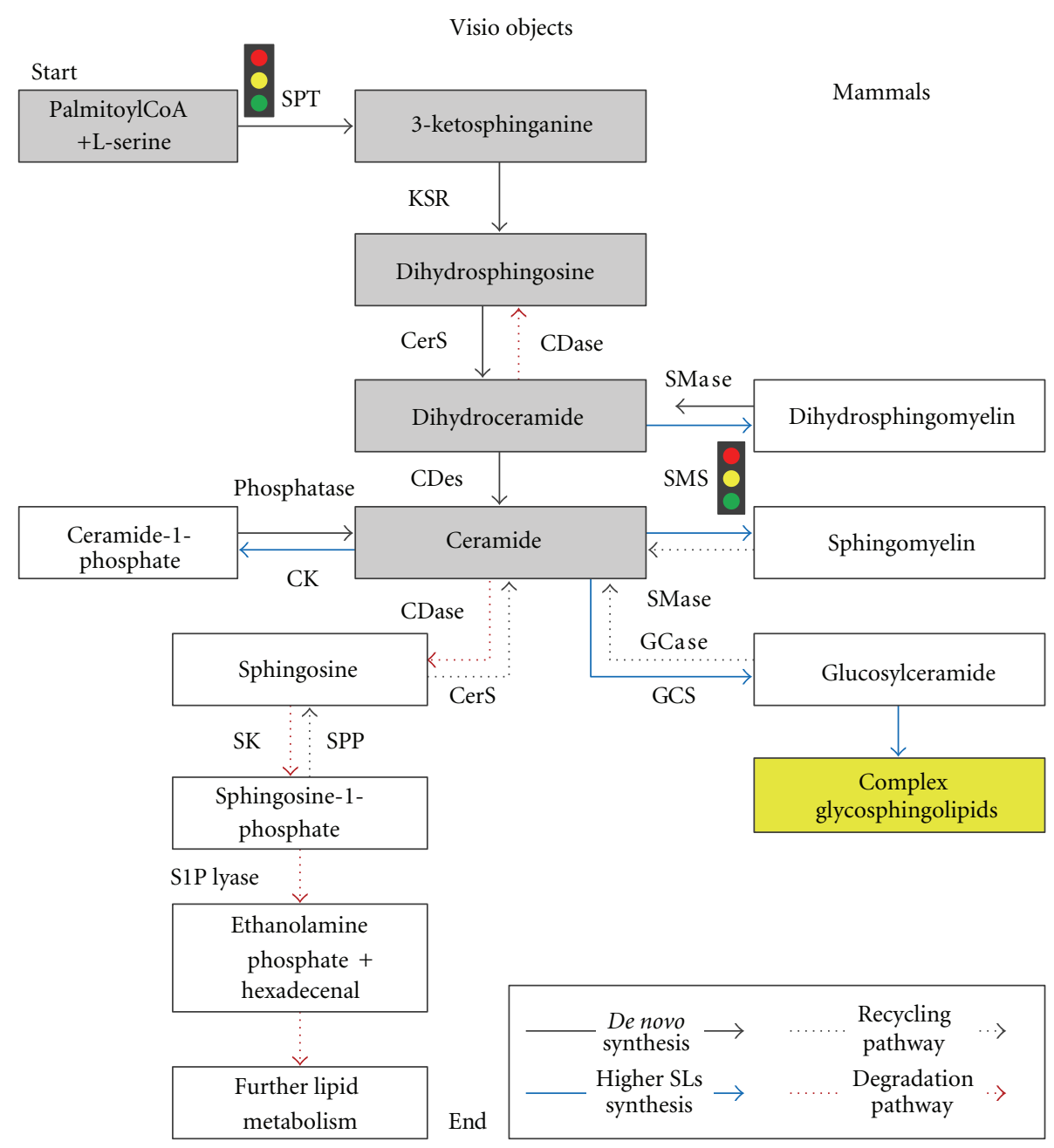

Figure 2: A simplified diagram of sphingolipid metabolism in mammals. The key regulatory synthetic steps are indicated by the "traffic light” symbols. SPT: Serine Palmitoyltransferase; 3-KSR: 3-Ketosphingosine Reductase; CerS: Ceramide Synthase; CDase: Ceramidase; CDes: Ceramide Desaturase; SMS: Sphingomyelin Synthase; SMase: Sphingomyelinase; CK: Ceramide Kinase; GCS: Glucosylceramide Synthase; GCase: Glycosidases; SK: Sphingosine Kinase; SPP: Sphingosine-1-Phosphate Phosphatase; S1P: Sphingosine-1-Phosphate.

complex phosphosphingolipids depending on the host organism. For example, in animal cells ceramide is a substrate for sphingomyelin (SM) synthase to produce SM [35]. In contrast, fungi and higher plants utilise phytoceramide to produce inositol phosphorylceramide (IPC) as their principal phosphosphingolipid, a reaction catalysed by IPC synthase $[36,37]$. In these organisms IPC is later glycosylated to produce more complex phosphosphingolipids, for example, mannose-IPC (MIPC), in yeast [38, 39]. Finally, the protozoa (exemplified by the Kinetoplastidae) represent a distinct third group in which ceramide [21] acquires a phosphorylinositol head group from phosphatidylinositol (PI) to produce IPC via IPC synthase [40] (Figure 3).

The synthesis of complex sphingolipids such as SM are key regulatory synthetic steps, as the rate of synthesis not only decreases the amount of ceramide, but also indirectly increases the total amount of ceramide-containing molecules that potentially could be degraded/catabolised to form ceramide.
Importantly, in such biosynthetic steps the evolutionarily divergent SM and IPC synthases are central in controlling the delicate balance of glycerolipids (PI/PC in and diacylglycerol-DAG out) on one hand, and sphingolipids (phytoceramide/ceramide in and IPC/SM out) on the other. Therefore, these enzymes have an important role as regulators of proapoptotic ceramide and promitogenic DAG [41]. In addition to a mitogenic role, DAG has also been attributed to play a role in several enzyme activation and regulatory functions $[1,2]$. Notably, IPC synthase inhibitors are acutely fungicidal, with the accumulation of ceramide proposed to induce apoptosis [42]. Thus this enzyme represents an attractive target for antifungals and more recently this has been extended to the kinetoplastid protozoa [43,44].

2.2. Recycling, Salvage, and Degradation. In addition to the de novo synthesis, the recycling, salvage, and degradation pathways modulate cellular levels of sphingolipids. These pathways operate in the direction of ceramide regeneration from 


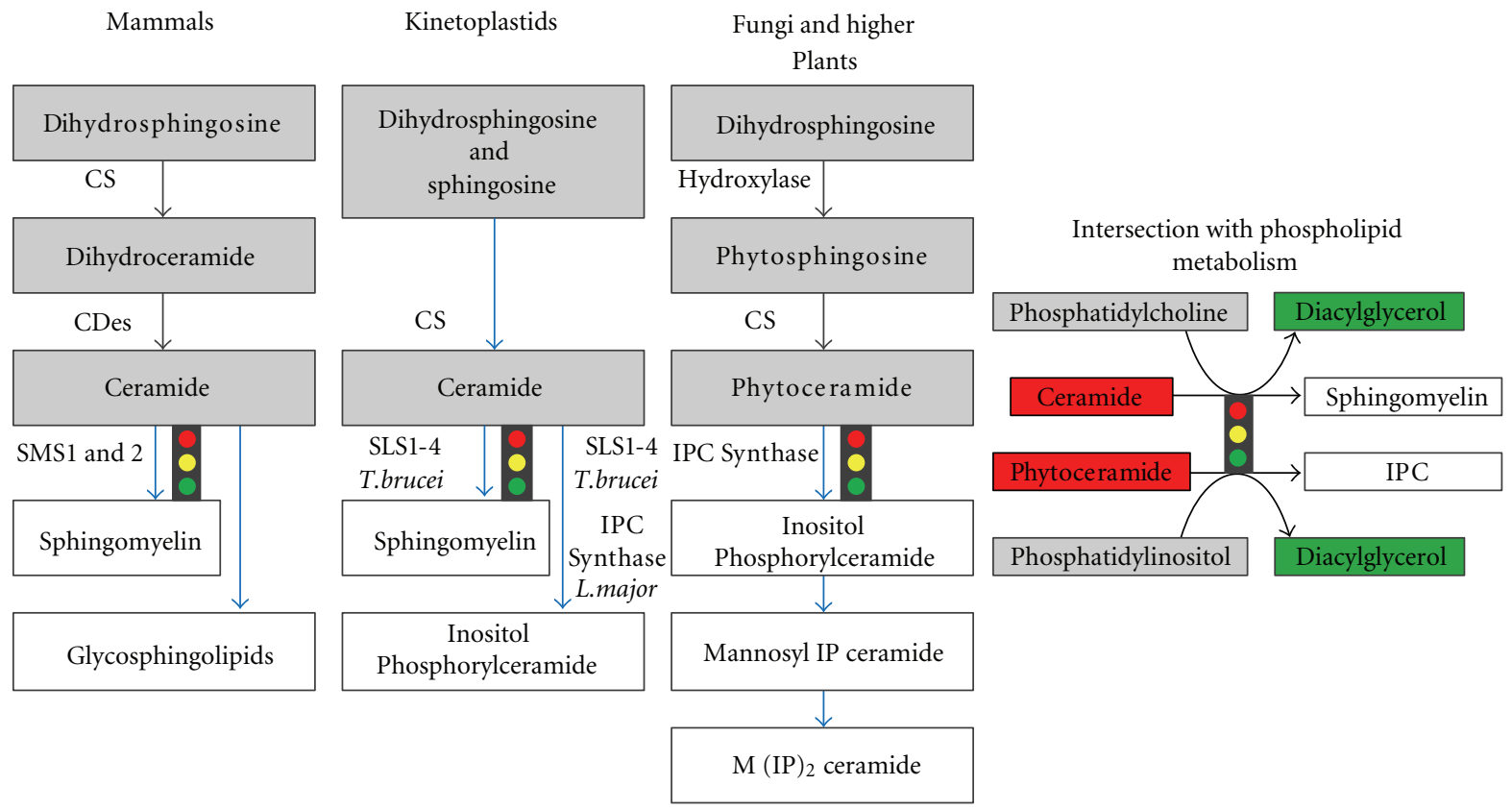

FIGURE 3: Divergence in the postceramide biosynthetic steps highlighting the conserved intersection with phospholipid metabolism as a regulator of the balance between promitogenic diacylglycerol (DAG) and proapoptotic ceramide. The key regulatory synthetic steps are indicated by the "traffic light" symbols. CS: Ceramide Synthase; CDes: Ceramide Desaturase; SMS: Sphingomyelin Synthase; SL: Sphingolipid; IPC: Inositol Phosphorylceramide; PC: Phosphatidylcholine.

complex sphingolipid reservoirs, for example glycosphingolipids (GSLs) and (SMs), through the action of specific hydrolases and phosphodiesterases.

Sphingolipid recycling can be categorised as either lysosomal or nonlysosomal degradation. In lysosomal degradation, catabolism of GSLs occurs as sugar residues are cleaved leading to the formation of glucosylceramide and galactosylceramide. In turn, specific $\beta$-glucosidases and galactosidases hydrolyse these lipids to form ceramide which can then be subsequently deacylated by an acid ceramidases to form sphingosine $[12,45]$, which can then be salvaged to form ceramide by reacylation. Defects in the function of these enzymes lead to a variety of lysosomal storage disorders such as Gaucher, Sandhoff, and Tay-Sachs diseases, resulting from the impairment of membrane degradation [46]. This will be discussed in more detail later.

Degradation of sphingolipids is a necessary part of maintaining lipid homeostasis, thus SM levels are maintained by catabolic action of sphingomyelinases (SMases), either neutral or acidic, releasing ceramide and the corresponding headgroup, phosphorylcholine in the case of SM. Acid sphingomyelinase (aSMase) was the first cloned human SMase and was initially assumed to be not much more than a housekeeping gene with a prominent role in the turnover of sphingomyelin in the lysosome. However, unusually aSMase has revealed itself to encode two unique enzymes through the differential trafficking of a single-protein precursor [47]. In addition to the commonly studied lysosomal aSMase, an alternative form is secreted extracellularly and may have a role in the nonlysosomal hydrolysis of SM both in the outer leaflet of the plasma membrane and in lipoproteins in the bloodstream [48]. These studies indicate that ceramide production by sphingolipid hydrolysis in different cellular or extracellular locations may provide different metabolic effects and biological impacts. Indeed, the nonlysosomal degradation of SM is catalysed by neutral and alkaline SMases in a variety of intracellular and extracellular locations. The least studied of these SMases, the alkaline SMase (Alk-SMase), is highly tissue specific with trypsin resistance and bile salt dependency and has a key role in the dietary acquisition of ceramide by digesting SM in the gut [49]. Notably, animal studies have shown Alk-SMase is specifically down regulated in colon cancer, while membrane SM accumulates. The supplementation of dietary SM can prevent the promotion of further colonic tumors [50].

SMases are commonly activated by growth factors, cytokines, chemotherapeutic agents, irradiation and nutrient removal [51], and though they can differ in their subcellular localisation and tissue specificity, all are thought to regulate the local ceramide concentration and any corresponding stress-induced responses [52]. Ceramide and associated metabolites, such as sphingosine-1-phosphate, are known to function as second messengers, stimulating various biological activities in mammalian cells, including the activation of protein-kinases and/or protein-phosphatases 2A [53]. Increased levels of ceramides can exert antiproliferation effects, induce apotosis, and play major roles in mitogenesis and endocytosis. There is a growing body of evidence that suggests $\mathrm{Mg}^{2+}$-dependent neutral sphingomyelinases (nSMases) are the major source for stress-induced ceramide 
production [51]. nSMases are ubiquitously expressed in mammalian cells, predominately membrane bound on the outer leaflet of the plasma membrane where most of the SM is located [52]. Other mammalian nSMases localise to the ER, where the predicted low abundance of SM has led to speculation that they may have additional lipid substrates such as lyso-platelet-activating factor [54]. In all cases of sphingolipid catabolism, the released ceramide can be either recycled into sphingolipid synthesis or degraded to sphingosine $[12,45]$. The resultant sphingosine, produced from either pathway, is either recycled into sphingolipid biosynthesis or phosphorylated by a cytosolic sphingosine kinase (SK) yielding sphingosine-1-phosphate (S1P). S1P can itself be dephosphorylated back to sphingosine or irreversibly degraded by S1P lyase into the nonsphingolipid species ethanolamine phosphate and hexadecenal, representing a unique exit point from the sphingolipid metabolic pathway $[12,45]$. In fact this is the mechanism by which the kinetoplastid Leishmania obtain ethanolamine [21].

Another kinetoplastid, Trypanosoma brucei, has shown that an ER nSMase directly involved in sphingolipid catabolism is essential because its formation of ceramide is required for post-Golgi sorting and deposition of the essential glycosylphosphatidylinositol-anchored variant surface glycoprotein on the cell surface [55]. Similarly, the Leishmania nSMase is essential for virulence and, whilst able to catabolise inositol phosphorylceramide (IPC), demonstrated greater activity with SM [56].

The corresponding yeast nSMase homologue (Isc1) is also capable of IPC catabolism, generating ceramide. During early growth Isclp resides in the ER, but in late logarithmic growth it is found in the outer leaflet of the mitochondria, where the resulting ceramide formation plays a crucial role in the reprogramming of mitochondrial gene expression during the transition from anaerobic to aerobic metabolism, coupled with a change in carbon source, that is, glucose to ethanol $[57,58]$.

\section{Ceramide Homeostasis}

As discussed, ceramides are central intermediates of sphingolipid metabolism. In addition to forming the basis of complex sphingolipids, ceramide is a bioactive molecule that regulates a myriad of cellular pathways including apoptosis, cell senescence, the cell cycle, and differentiation [59]. In addition, this lipid species is involved in the cell response to stress challenge. Notably, several anticancer drugs, for example, etoposide and daunorubicin, have been found to function by elevating the level of cellular ceramide triggering apoptosis [60-63]. The apoptotic role of ceramide [64, 65] contrasts with that of the mitogenic agonist DAG. Whilst the former stimulates signal transduction pathways associated with cell death or growth inhibition, DAG activates the various isoforms of protein kinase $\mathrm{C}$ associated with cell growth and survival. Thus, ceramide and DAG generation may regulate cellular homeostasis by inducing death and growth, respectively. Given that ceramide and DAG are a substrate and a byproduct, respectively, of SM and IPC synthases, these enzymes are hypothesized to play a central role in homeostasis [9].

Recently, a human SM synthase-related protein has been shown to function as a ceramide sensor [66] with a crucial role in protecting cells against ceramide-induced cell death. Disruption of this sensor leads to ceramide accumulation in the endoplasmic reticulum and mitochondrial-mediated apoptosis. This process is suppressed by targeting a ceramidase to mitochondria indicating that transfer of ceramide from the endoplasmic reticulum to mitochondria, via an unknown mechanism, is a key step in committing cells to death. The presence of a mitochondrial ceramide synthase has also been reported and hypothesized to play a role in this apoptotic process [67]. Together, these findings provide mechanistic evidence for the proapoptotic accumulation of ceramide in the mitochondria and demonstrate that the regulation of ceramide homeostasis is a vital cellular function.

\section{Defects in Sphingolipid Metabolism}

Despite sphingolipids being minor components in some cells, their accumulation in certain cells and tissues forms the basis of many human diseases.

4.1. Sphingolipidoses. Defects in sphingolipid catabolism, that is, lipid hydrolases, form the basis of a wide variety of human diseases. These diseases, collectively known as sphingolipidoses (Figure 4), belong to the lysosomal storage diseases and are inherited disorders characterised by accumulations in specific lipids in certain tissues and/or organs.

The most common is Gaucher disease, in which glucosylceramide accumulates due to a deficiency of glucosylceramide- $\beta$-glucosidase, causing changes in the specialised membrane microdomains termed lipid rafts. This in turn seems to impair lipid and protein sorting and consequently causes the pathology characterising this disorder. For example, lipid rafts are necessary for correct insulin signalling, and a perturbed lipid raft composition impairs insulin signalling leading to the insulin-resistance observed in patients with Gaucher disease $[68,69]$.

Fabry disease is an X-chromosomal-linked inherited deficiency of lysosomal $\alpha$-galactosidase A, causing deposition of globotriaosylceramide in the lysosomes of endothelial, perithelial and smooth-muscle cells of blood vessels. This leads to renal, cardiac and/or cerebral complications and, most commonly, death before the age of $50[70,71]$.

Tay-Sachs disease or GM2-gangliosidosis comes in various forms, the most extreme, infantile form being caused by defects in $\beta$-hexosaminidase $\mathrm{A}$ and has a high heterozygote frequency $(1: 27)$ among Ashkenazi Jews. This condition leads to death between the second and fourth years of life $[72,73]$.

Sandhoff disease is characterized by storage of negatively charged glycolipids and elevation of uncharged glycolipids. This disease has various clinical forms, infantile, juvenile, and adult, all with varying pathological manifestations, including a chronic variant similar to Tay-Sachs disease [74, 75]. 


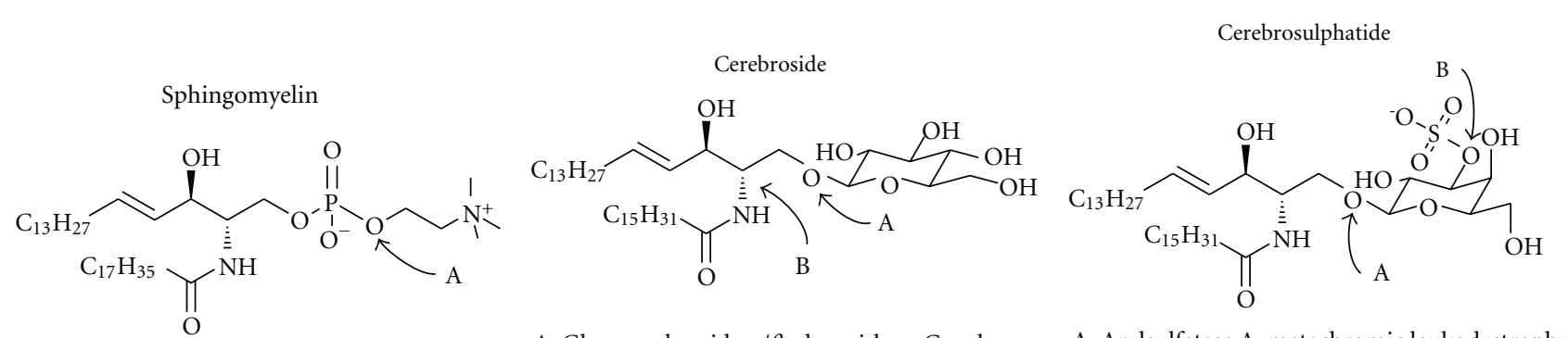

A. Glucocerebrosidase/ $\beta$-glucosidase, Gaucher B. Acid ceramidase, Farber

(b)
A. Arylsulfatase A, metachromic leukodystrophy

B. Galactocerebrosidase, Krabbe

(c) (a)

GM1 ganglioside

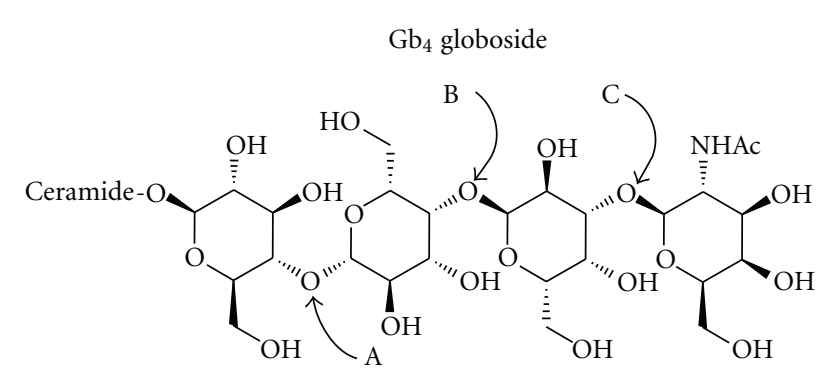

A. Galactosylceramide- $\beta$-galactosidase/GM1- $\beta$ galactosidase, GM1 gangliosidosis

B. $\alpha$-galactosidase A, Fabry

C. $\beta$-hexosaminidase A, B, Sandhoff

(d)

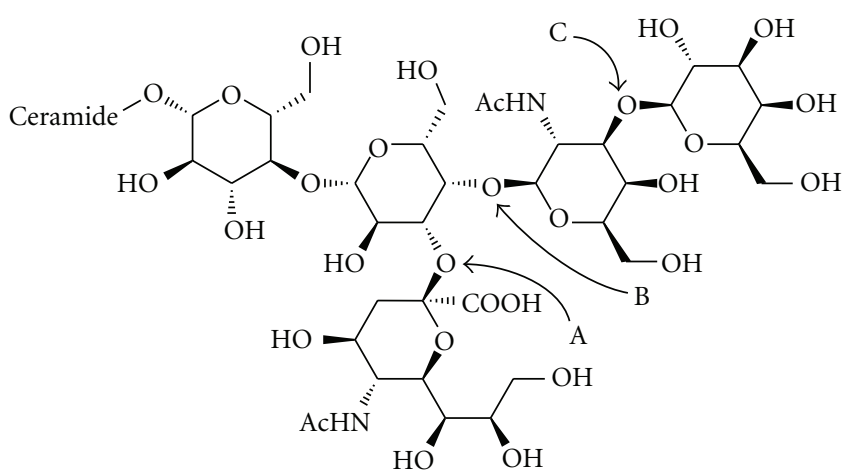

A. Sialidase, sialidosis

B. $\beta$-hexosaminidase $\mathrm{A}, \mathrm{GM} 2$ gangliosidosis (TaySachs/Sandhoff/AB variant)

C. GM1- $\beta$-galactosidase, GM1 gangliosidosis

(e)

FIGURE 4: Defects in mammalian sphingolipid catabolism and their associated sphingolipidoses. The enzymes responsible are indicated at the glycosidic linkages on which they act.

The inherited Niemann-Pick disease (types A and B) is characterised by a deficiency in the lysosomal acidic SMase, causing an accumulation not only of sphingomyelin but also of glycosphingolipids, sphingosine and others in multilamellar storage bodies [76].

There are many other related and associated genetic diseases, Metachromatic Leukodystrophy caused by a deficiency of arylsulfatase A, Krabbe disease or globoid cell leukodystrophy caused by a deficiency of galactosylceramide- $\beta$-galactosidase and Farber disease caused by a deficiency of lysosomal acid ceramidase causing storage of excess ceramide in the lysosomes. For further details of these and other sphingolipid metabolic diseases, refer to an excellent review by Kolter and Sandhoff [77].

4.2. Hereditary Sensory Neuropathy. Clinical disorders are also associated with alterations in SPT activity, although a complete lack of SPT activity is predicted to be embryonically lethal. The inherited disease hereditary sensory neuropathy type I (HSN1) is a progressive degeneration of lower limb sensory and autonomic neurons and has been associated with mutations in the human LCB1 gene [78, 79]. LCB1
(SPTLC1) mutations confer dominant negative effects on SPT, thus substantially reducing SPT activity and hence the rate of de novo synthesis of sphingolipids [80]. Recently, point mutations have been found in the catalytic SPT subunit (LCB2 or SPTLC2) in patients suffering from HSN1. These were confirmed to affect SPT activity using an in vitro system. No mutations were observed in the third (SPTLC3) subunit in these patients [81].

Point mutations in the SPT complex also affect SPT activity in terms of substrate specificity and alanine can be used instead of serine in the condensation with palmitoyl-CoA, resulting in the formation and accumulation of 1-deoxy-sphinganine in the serum of these patients [82].

4.3. Alzheimer's Disease. A relatively recent discovery was the highly altered sphingolipid metabolism in brain cells in Alzheimer's disease [83]. The latest study has highlighted the key role of an nSMase in the disease by promoting the damaging effects of fibrillar amyloid- $\beta$ 1-42 peptide-activated astroglia through ceramide production and thus apoptosis in neuronal cells [84]. 
In addition, SPT has been shown to be downregulated by the amyloid precursor protein [85]. This novel physiological function of the amyloid precursor protein suggests that SPT and sphingolipid metabolism is involved in Alzheimer's disease pathology.

4.4. Other Diseases. Obesity and its established association with insulin resistance, type 2 diabetes, and cardiovascular disease are directly and/or indirectly involved in the overaccumulation of long-chain fatty acids. The resulting surplus to the storage capacity of adipose tissue results in deposition in nonadipose tissues, such as the liver, muscle, heart, and pancreatic islets. This leads to deleterious effects, not only as atherosclerosis, but excess lipids are also forced into alternative nonoxidative pathways resulting in the formation of reactive lipid moieties, such as sphingolipids, that promote metabolically relevant cellular dysfunction (lipotoxicity) and programmed cell death (lipoapoptosis) [86-88].

\section{Sphingolipid Biosynthesis: An Attractive Drug Target}

Due to the complexities of sphingolipid metabolism and associated defects in a variety of tissue types and cell compartments, there is a significant challenge in the understanding, diagnosis, and treatment of genetic diseases such as those discussed above. However, clinical manipulation sphingolipid metabolism will prove key in the treatment of these conditions; in addition it is becoming clear that by inducing the accumulation of proapoptotic ceramide, therapies for cancer and infectious disease may be developed.

5.1. Sphingolipidoses. The general strategy to treating the inherited human diseases involving sphingolipid metabolism, the sphingolipidoses is the restoration of the defective lysosomal degradation. These include enzyme replacement, heterologous bone marrow transplantation as a form of cellmediated therapy, gene therapy and the use of chemical chaperones for enzyme-enhancement therapy. An alternative strategy is the reduction of substrate influx into the lysosomes using substrate reduction (substrate deprivation) therapy ([77] and references therein).

5.2. Cancer. The roles of ceramide in diverse cellular responses to stress, particularly apoptosis, has been discussed above and as mentioned elevated ceramide often result from treatment with anticancer drugs and also irradiation. Therefore the manipulation of sphingolipid biosynthesis and homeostasis to elevate ceramide levels and induce programmed cell death is a viable strategy for anticancer therapies [89]. Conversely, dysregulation of ceramide metabolism affects the cellular response to chemotherapy or other anticancer regimens by rendering the cells more resistant to killing; in these cases therapeutic manipulation of ceramide metabolism could overcome this resistance [90, 91]. Further developments in the manipulation of sphingolipid metabolism as an anticancer strategy will undoubtedly follow with the breakthrough discovery that FTY720, a water-soluble sphingosine analogue effective in many cancer models which acts by downregulating nutrient transporter proteins in cancer cells at least partially via ceramide generation [92]. The resulting starvation induces a homeostatic autophagy selectively in cancer cells sensitive to nutrient limitation, while normal cells have the ability to adapt and survive by becoming quiescent. Notably AAL-149, an FTY720 analogue, similarly kills patient-derived leukaemic cells, but not cells of healthy donors, without the dose-limiting toxicity of FTY720. Thus, by targeting the sphingolipid metabolism of cancer cells rather than any specific oncogenic defect, such compounds should have potent activity against a range of tumours, particularly if applied in combination with inhibitors of autophagy.

5.3. Pathogens. The essential functions of sphingolipids, coupled with the divergence of the biosynthetic pathway between mammals and eukaryotic pathogens have resulted in the investigation of the biosynthetic enzymes as possible drug targets for antifungal and antiprotozoals. Consequently, inhibitors of many of the steps in sphingolipid biosynthesis have been described $[2,43]$. Before the synthesis of ceramide/ phytoceramide the sphingolipid biosynthetic pathway is largely conserved across evolution. At least in part because of this, all the inhibitors identified as targeting fungal enzymes in this part of the biosynthetic pathway are nonselective and inhibit the mammalian orthologues [43]. This has curtailed their clinical application as anti-fungal agents, for example fumonisin $B_{1}$ which inhibits the fungal phytoceramide synthase demonstrated mammalian toxicity [93]. In contrast the post-ceramide divergence represented by the absence of IPC synthase and inositol-based sphingolipids in mammalian cells, highlights the therapeutic potential of inhibitors targeting fungal IPC synthases. Such inhibitors could result in selective antifungal drugs with minimal host toxicity. Additionally, the identification and isolation of functional orthologues of the fungal enzyme in the kinetoplastid protozoan parasites (Leishmania spp., Trypanosoma brucei and Trypanosoma cruzi) indicated that IPC synthase is a valid target for antiprotozoal compounds [3]. One of the T. brucei sphingolipid synthases, a novel bifunctional enzyme catalysing the synthesis of both IPC and SM, is essential for parasite growth and can be inhibited in vitro by the antifungal aureobasidin A at low nanomolar concentrations [43]. As the causative agent of Chagas' disease, Trypanosoma cruzi has a complex lifecycle with an essential intracellular stage in vertebrate hosts, in addition to an extracellular existence in an insect vector. Necessary to persistence of the lifecycle is the synthesis of surface glycosylphosphatidylinositol (GPI) anchored glycoconjugates, meaning that the biosynthesis of GPI anchors is attractive target for new therapies against Chagas' disease [93]. As many T. cruzi GPI anchors contain IPC as the lipid portion, the sole IPC synthase is highlighted as a new therapeutic target for Chagas disease.

To date only the natural compounds-aureobasidin A $[33,94,95]$, Khafrefungin [94], and Rustmicin [96, 97] have been reported as potent inhibitors of the fungal IPC synthase. As discussed, there is an inhibitory effect of aureobasidin A against the Kinetoplastid enzyme orthologues [43, 98, 99], although the specificity of this remains unclear $[3,100,101]$. 
Unfortunately, further development of all the three known inhibitors of IPC synthase has stalled either due to lack of physical properties required for an acceptable pharmacokinetic profile $[42,102]$, or because their highly complex structures render chemical synthesis challenging. Moreover, the few synthetic efforts to modify or synthesise analogues that have been reported, resulted in compounds with either reduced or no activity $[103,104]$. What has proven more successful however is the development of substrate (ceramide) analogues, with targeted inhibition against the protozoal IPC synthases in cellulo [105].

In addition to sphingolipid synthesis as a therapeutic target against parasitic protozoa, degradation of sphingolipids similarly is an area providing new opportunities for antiprotozoal compounds. Leishmania spp. use sphingolipid biosynthesis to generate ethanolamine (Etn), essential for the survival and differentiation from procyclics to virulent metacyclics [21]. A likely starting point for Etn production is the degradation of IPC, and a putative neutral SMase and/or IPC hydrolase (IPCase), designated ISCL was identified in the L. major genome [106]. ISCL showed much greater activity against non-self SM over IPC, suggesting a role in host SL degradation confirmed by ISCL null mutants failing to induce lesions in susceptible BALB/c mice. Further investigation revealed that host SL catabolism by Leishmania was essential to resist the harsh acidic environment in the phagolysosomes of macrophages [107]. These findings reveal that SL catabolism, as well as anabolism, by Leishmania is necessary for proliferation of the parasite in the mammalian host, making the ISCL enzyme an equally attractive target for inhibition studies. Trypanosoma cruzi invades mammalian cells by attaching and mimicking injury to the host plasma membrane, inducing a repair process that involves the $\mathrm{Ca}^{2+}$-dependent exocytosis of lysosomes [108]. As host acid sphingomyelinase (aSMase) is delivered by lysosomes to the plasma membrane, its ceramide-generating activity promotes rapid endocytosis to internalise the seemingly damaged membrane and the attached parasites. Consequently any inhibition or reduction of this lysosomal aSMase blocks T. cruzi invasion, though subsequent treatment with an extracellular sphingomyelinase can restore the infection to normal levels. In a similar approach it has been demonstrated that inhibition of host cell SPT, and so sphingolipid biosynthesis, by myriocin, suppresses hepatitis $\mathrm{C}$ virus replication [109]. In addition, it has emerged that ceramide induces activation of double-stranded RNA-dependent protein kinasemediated antiviral response [110]. These recent findings suggest that manipulation of host sphingolipid metabolism may provide a new combined therapeutic strategy for treatment of both protozoal and viral infections.

\section{Perspective}

Recent studies of the genetic, biochemical and cell biology of sphingolipids have provided exciting new insights into their function, regulation and control, allowing the consideration of future manipulations to aid the fight against human diseases including cancer and major fungal and parasitic infections. In addition, this information may ultimately aid the treatment of several rare genetic disorders (e.g. the sphingolipidoses) and, perhaps, Alzheimer's disease. However, in most cases these studies are at an early stage and further work is required to establish proof of concept. This will undoubtedly be achieved as progress towards a fuller understanding of the complex and multilayered metabolic pathways of sphingolipid metabolism is realized, and as inhibitors of the enzymes involved become available.

$\begin{array}{ll}\text { Abbreviations } \\ \text { SM: } & \text { Sphingomyelin } \\ \text { IPC: } & \text { Inositol phosphorylceramide } \\ \text { MIPC: } & \text { Mannose-IPC } \\ \text { PI: } & \text { Phosphatidylinositol } \\ \text { DAG: } & \text { Diacylglycerol } \\ \text { CS: } & \text { Ceramide synthase } \\ \text { CDes: } & \text { Ceramide desaturase } \\ \text { SMS: } & \text { Sphingomyelin synthase } \\ \text { SL: } & \text { Sphingolipid } \\ \text { PC: } & \text { Phosphatidylcholine } \\ \text { SMases: } & \text { Sphingomyelinases } \\ \text { aSMase: } & \text { Acid sphingomyelinase } \\ \text { Alk-SMase: } & \text { Alkaline SMase } \\ \text { SPT: } & \text { Serine palmitoyltransferase } \\ \text { 3-KSR: } & \text { 3-Ketosphingosine reductase } \\ \text { CerS: } & \text { Ceramide synthase } \\ \text { CDase: } & \text { Ceramidase } \\ \text { CDes: } & \text { Ceramide desaturase } \\ \text { SMS: } & \text { Sphingomyelin synthase } \\ \text { SMase: } & \text { Sphingomyelinase } \\ \text { CK: } & \text { Ceramide kinase } \\ \text { GCS: } & \text { Glucosylceramide synthase } \\ \text { GCase: } & \text { Glycosidases } \\ \text { SK: } & \text { Sphingosine kinase } \\ \text { SPP: } & \text { Sphingosine-1-phosphate phosphatase } \\ \text { S1P: } & \text { Sphingosine-1-phosphate } \\ \text { HSN1: } & \text { Hereditary sensory neuropathy type I. } \\ & \end{array}$

\section{Author Contribution}

Both Simon A. Young and John G. Mina contributed equally to this paper.

\section{Acknowledgments}

Research in TKS's laboratory is supported in part by Wellcome Trust project Grants (086658 and 093228) and studentships from the Biotechnology and Biological Sciences Research Council and SUSLA. Research in PWD's laboratory is supported in part by Wellcome Trust project Grant (094759), a grant from the Open Lab Foundation, studentships from the Engineering and Physical Sciences and Medical Research Councils and the Wolfson Research Institute.

\section{References}

[1] D. E. Metzler, Biochemistry; The Chemical Reactions of Living Cells, vol. 1-2, Elsevier, 2nd edition, 2003. 
[2] A. H. Merrill and K. Sandhoff, "Sphingolipids: metabolism and cell signalling," in Biochemistry of Lipids, Lipoproteins and Membranes, D. E. Vance and J. E. Vance, Eds., pp. 373-407, Elsevier, Amsterdam, The Netherlands, 2002.

[3] P. W. Denny, H. Shams-Eldin, H. P. Price, D. F. Smith, and R. T. Schwarz, "The protozoan inositol phosphorylceramide synthase: a novel drug target that defines a new class of sphingolipid synthase," Journal of Biological Chemistry, vol. 281, no. 38, pp. 28200-28209, 2006.

[4] M. I. Gurr, J. L. Harwood, and K. N. Frayn, Lipid Biochemistry: An Introduction, Blackwell Science, 5th edition, 2002.

[5] G. Van Meer and Q. Lisman, "Sphingolipid transport: rafts and translocators," Journal of Biological Chemistry, vol. 277, no. 29, pp. 25855-25858, 2002.

[6] A. Huwiler, T. Kolter, J. Pfeilschifter, and K. Sandhoff, "Physiology and pathophysiology of sphingolipid metabolism and signaling," Biochimica et Biophysica Acta, vol. 1485, no. 2-3, pp. 63-99, 2000.

[7] J. Ohanian and V. Ohanian, "Sphingolipids in mammalian cell signalling," Cellular and Molecular Life Sciences, vol. 58, no. 14, pp. 2053-2068, 2001.

[8] O. Cuvillier, "Sphingosine in apoptosis signaling," Biochimica et Biophysica Acta, vol. 1585, no. 2-3, pp. 153-162, 2002.

[9] B. J. Pettus, C. E. Chalfant, and Y. A. Hannun, "Ceramide in apoptosis: an overview and current perspectives," Biochimica et Biophysica Acta, vol. 1585, no. 2-3, pp. 114-125, 2002.

[10] R. Buccoliero and A. H. Futerman, "The roles of ceramide and complex sphingolipids in neuronal cell function," Pharmacological Research, vol. 47, no. 5, pp. 409-419, 2003.

[11] Y. A. Hannun, C. R. Loomis, A. H. Merrill, and R. M. Bell, "Sphingosine inhibition of protein kinase $\mathrm{C}$ activity and of phorbol dibutyrate binding in vitro and in human platelets," Journal of Biological Chemistry, vol. 261, no. 27, pp. 12604 12609, 1986.

[12] Y. A. Hannun and L. M. Obeid, "Principles of bioactive lipid signalling: lessons from sphingolipids," Nature Reviews Molecular Cell Biology, vol. 9, no. 2, pp. 139-150, 2008.

[13] S. T. Pruett, A. Bushnev, K. Hagedorn et al., "Thematic review series: sphingolipids-biodiversity of sphingoid bases ("sphingosines") and related amino alcohols," Journal of Lipid Research, vol. 49, no. 8, pp. 1621-1639, 2008.

[14] E. Fahy, S. Subramaniam, H. A. Brown et al., "A comprehensive classification system for lipids," Journal of Lipid Research, vol. 46, no. 5, pp. 839-861, 2005.

[15] E. Fahy, S. Subramaniam, R. C. Murphy et al., "Update of the LIPID MAPS comprehensive classification system for lipids," Journal of Lipid Research, vol. 50, supplement, pp. S9-S14, 2009.

[16] R. M. Bell, A. H. Merrill Jr., Y. A. Hannun et al., Advances in Lipid Research: Sphingolipids, Part A: Functions and Breakdown Products, vol. 25, 1993.

[17] R. M. Bell, A. H. Merrill Jr., Y. A. Hannun, and R. M. Bell, "Introduction: sphingolipids and their metabolites in cell regulation," Advances in lipid research, vol. 25, pp. 1-24, 1993.

[18] A. H. Merrill, E. M. Schmelz, D. L. Dillehay et al., "Sphingolipids - the enigmatic lipid class: biochemistry, physiology and pathophysiology," Toxicology and Applied Pharmacology, vol. 142, no. 1, pp. 208-225, 1997.

[19] M. O. Pata, Y. A. Hannun, and C. K.-Y. Ng, "Plant sphingolipids: decoding the enigma of the Sphinx," New Phytologist, vol. 185, no. 3, pp. 611-630, 2010.

[20] N. Bartke and Y. A. Hannun, "Bioactive sphingolipids: metabolism and function," Journal of Lipid Research, vol. 50, supplement, pp. S91-S96, 2009.
[21] K. Zhang, F. F. Hsu, D. A. Scott, R. Docampo, J. Turk, and S. M. Beverley, "Leishmania salvage and remodelling of host sphingolipids in amastigote survival and acidocalcisome biogenesis," Molecular Microbiology, vol. 55, no. 5, pp. 15661578, 2005.

[22] B. Ségui, N. Andrieu-Abadie, J. P. Jaffrézou, H. Benoist, and T. Levade, "Sphingolipids as modulators of cancer cell death: potential therapeutic targets," Biochimica et Biophysica Acta, vol. 1758, no. 12, pp. 2104-2120, 2006.

[23] K. Hanada, "Serine palmitoyltransferase, a key enzyme of sphingolipid metabolism," Biochimica et Biophysica Acta, vol. 1632, no. 1-3, pp. 16-30, 2003.

[24] P. W. Denny, D. Goulding, M. A. J. Ferguson, and D. F. Smith, "Sphingolipid-free Leishmania are defective in membrane trafficking, differentiation and infectivity," Molecular Microbiology, vol. 52, no. 2, pp. 313-327, 2004.

[25] M. Chen, G. Han, C. R. Dietrich, T. M. Dunn, and E. B. Cahoon, "The essential nature of sphingolipids in plants as revealed by the functional identification and characterization of the Arabidopsis LCB1 subunit of serine palmitoyltransferase," Plant Cell, vol. 18, no. 12, pp. 3576-3593, 2006.

[26] H. Ikushiro, H. Hayashi, and H. Kagamiyama, "Bacterial serine palmitoyltransferase: a water-soluble homodimeric prototype of the eukaryotic enzyme," Biochimica et Biophysica Acta, vol. 1647, no. 1-2, pp. 116-120, 2003.

[27] M. C. Raman, K. A. Johnson, D. J. Clarke, J. H. Naismith, and D. J. Campopiano, "The serine palmitoyltransferase from sphingomonas wittichii RW1: an interesting link to an unusual acyl carrier protein," Biopolymers, vol. 93, no. 9, pp. 811-822, 2010.

[28] K. Gable, H. Slife, D. Bacikova, E. Monaghan, and T. M. Dunn, "Tsc3p is an 80 -amino acid protein associated with serine palmitoyltransferase and required for optimal enzyme activity," Journal of Biological Chemistry, vol. 275, no. 11, pp. 7597-7603, 2000.

[29] G. Han, S. D. Gupta, K. Gable et al., "Identification of small subunits of mammalian serine palmitoyltransferase that confer distinct acyl-CoA substrate specificities," Proceedings of the National Academy of Sciences of the United States of America, vol. 106, no. 20, pp. 8186-8191, 2009.

[30] T. Hornemann, A. Penno, M. F. Rütti et al., "The SPTLC3 subunit of serine palmitoyltransferase generates short chain sphingoid bases," Journal of Biological Chemistry, vol. 284, no. 39, pp. 26322-26330, 2009.

[31] Y. Sugimoto, H. Sakoh, and K. Yamada, "IPC synthase as a useful target for antifungal drugs," Current Drug Targets, vol. 4, no. 4, pp. 311-322, 2004.

[32] P. E. Bromley, Y. O. Li, S. M. Murphy, C. M. Sumner, and D. V. Lynch, "Complex sphingolipid synthesis in plants: characterization of inositolphosphorylceramide synthase activity in bean microsomes," Archives of Biochemistry and Biophysics, vol. 417, no. 2, pp. 219-226, 2003.

[33] P. Rovina, A. Schanzer, C. Graf, D. Mechtcheriakova, M. Jaritz, and F. Bornancin, "Subcellular localization of ceramide kinase and ceramide kinase-like protein requires interplay of their Pleckstrin Homology domain-containing N-terminal regions together with C-terminal domains," Biochimica et Biophysica Acta, vol. 1791, no. 10, pp. 1023-1030, 2009.

[34] A. Raas-Rothschild, I. Pankova-Kholmyansky, Y. Kacher, and A. H. Futerman, "Glycosphingolipidoses: beyond the enzymatic defect," Glycoconjugate Journal, vol. 21, no. 6, pp. 295304, 2004.

[35] K. Huitema, J. Van Den Dikkenberg, J. F. H. M. Brouwers, and J. C. M. Holthuis, "Identification of a family of animal 
sphingomyelin synthases," EMBO Journal, vol. 23, no. 1, pp. 33-44, 2004.

[36] M. M. Nagiec, E. E. Nagiec, J. A. Baltisberger, G. B. Wells, R. L. Lester, and R. C. Dickson, "Sphingolipid synthesis as a target for antifungal drugs," Journal of Biological Chemistry, vol. 272, no. 15, pp. 9809-9817, 1997.

[37] W. Wang, X. Yang, S. Tangchaiburana et al., "An inositolphosphorylceramide synthase is involved in regulation of plant programmed cell death associated with defense in arabidopsis," Plant Cell, vol. 20, no. 11, pp. 3163-3179, 2008.

[38] R. C. Dickson and R. L. Lester, "Yeast sphingolipids," Biochimica et Biophysica Acta, vol. 1426, no. 2, pp. 347-357, 1999.

[39] R. L. Lester and R. C. Dickson, "Sphingolipids with inositolphosphate-containing head groups," Advances in Lipid Research, vol. 26, pp. 253-274, 1993.

[40] J. G. Mina, J. A. Mosely, H. Z. Ali et al., "A plate-based assay system for analyses and screening of the Leishmania major inositol phosphorylceramide synthase," International Journal of Biochemistry and Cell Biology, vol. 42, no. 9, pp. 1553-1561, 2010.

[41] J. C. M. Holthuis, F. G. Tafesse, and P. Ternes, "The multigenic sphingomyelin synthase family," Journal of Biological Chemistry, vol. 281, no. 40, pp. 29421-29425, 2006.

[42] N. H. Georgopapadakou, "Antifungals targeted to sphingolipid synthesis: focus on inositol phosphorylceramide synthase," Expert Opinion on Investigational Drugs, vol. 9, no. 8, pp. 1787-1796, 2000.

[43] J. G. Mina, S. Y. Pan, N. K. Wansadhipathi et al., "The Trypanosoma brucei sphingolipid synthase, an essential enzyme and drug target," Molecular and Biochemical Parasitology, vol. 168 , no. 1, pp. 16-23, 2009.

[44] S. S. Sutterwala, F. F. Hsu, E. S. Sevova et al., "Developmentally regulated sphingolipid synthesis in African trypanosomes," Molecular Microbiology, vol. 70, no. 2, pp. 281296, 2008.

[45] T. Kolter and K. Sandhoff, "Sphingolipids - their metabolic pathways and the pathobiochemistry of neurodegenerative diseases," Angewandte Chemie, vol. 38, no. 11, pp. 1532-1568, 1999.

[46] H. Schulze and K. Sandhoff, "Lysosomal lipid storage diseases," Cold Spring Harbor Perspectives in Biology, vol. 3, no. 6, 2011.

[47] S. L. Schissel, E. H. Schuchman, K. J. Williams, and I. Tabas, " $\mathrm{Zn}^{2+}$-stimulated sphingomyelinase is secreted by many cell types and is a product of the acid sphingomyelinase gene," Journal of Biological Chemistry, vol. 271, no. 31, pp. 1843118436, 1996.

[48] R. W. Jenkins, D. Canals, and Y. A. Hannun, "Roles and regulation of secretory and lysosomal acid sphingomyelinase," Cellular Signalling, vol. 21, no. 6, pp. 836-846, 2009.

[49] R. D. Duan, T. Bergman, N. Xu et al., "Identification of human intestinal alkaline sphingomyelinase as a novel ectoenzyme related to the nucleotide phosphodiesterase family," Journal of Biological Chemistry, vol. 278, no. 40, pp. 38528 38536, 2003.

[50] Y. Zhang, Y. Cheng, G. H. Hansen et al., "Crucial role of alkaline sphingomyelinase in sphingomyelin digestion: a study on enzyme knockout mice," Journal of Lipid Research, vol. 52, no. 4, pp. 771-781, 2011.

[51] T. Yabu, S. Imamura, M. Yamashita, and T. Okazaki, "Identification of $\mathrm{Mg}^{2+}$-dependent neutral sphingomyelinase 1 as a mediator of heat stress-induced ceramide generation and apoptosis," Journal of Biological Chemistry, vol. 283, no. 44, pp. 29971-29982, 2008.
[52] S. Tomiuk, K. Hofmann, M. Nix, M. Zumbansen, and W. Stoffel, "Cloned mammalian neutral sphingomyelinase: functions in sphingolipid signaling?" Proceedings of the $\mathrm{Na}$ tional Academy of Sciences of the United States of America, vol. 95, no. 7, pp. 3638-3643, 1998.

[53] A. Huwiler, T. Kolter, J. Pfeilschifter, and K. Sandhoff, "Physiology and pathophysiology of sphingolipid metabolism and signaling," Biochimica et Biophysica Acta, vol. 1485, no. 2-3, pp. 63-99, 2000.

[54] H. Sawai, Y. Okamoto, C. Luberto et al., "Identification of ISC1 (YERO19w) as inositol phosphosphingolipid phospholipase C in Saccharomyces cerevisiae," Journal of Biological Chemistry, vol. 275, no. 50, pp. 39793-39798, 2000.

[55] S. A. Young and T. K. Smith, "The essential neutral sphingomyelinase is involved in the trafficking of the variant surface glycoprotein in the bloodstream form of Trypanosoma brucei," Molecular Microbiology, vol. 76, no. 6, pp. 1461$1482,2010$.

[56] O. Zhang, M. C. Wilson, W. Xu et al., "Degradation of host sphingomyelin is essential for Leishmania virulence," Plos Pathogens, vol. 5, no. 12, Article ID e1000692, 2009.

[57] S. Vaena de Avalos, Y. Okamoto, and Y. A. Hannun, "Activiation and localization of inositolphosphosphingolipid phospholipase C Isc1p, to the mitochondria during growth of Saccharomyces cerevisiae," The Journal of Biological Chemistry, vol. 279, no. 12, pp. 11507-11545, 1998.

[58] H. Kitagaki, L. A. Cowart, N. Matmati et al., "ISC1-dependent metabolic adaptation reveals an indispensable role for mitochondria in induction of nuclear genes during the diauxic shift in Saccharomyces cerevisiae," Journal of Biological Chemistry, vol. 284, no. 16, pp. 10818-10830, 2009.

[59] J. C. M. Holthuis, T. Pomorski, R. J. Raggers, H. Sprong, and G. Van Meer, "The organizing potential of sphingolipids in intracellular membrane transport," Physiological Reviews, vol. 81, no. 4, pp. 1689-1723, 2001.

[60] R. Bose, M. Verheij, A. Halmovitz-Friedman, K. Scotto, Z. Fuks, and R. Kolesnick, "Ceramide synthase mediates daunorubicin-induced apoptosis: an alternative mechanism for generating death signals," Cell, vol. 82, no. 3, pp. 405-414, 1995.

[61] C. E. Chalfant, K. Rathman, R. L. Pinkerman et al., "De novo ceramide regulates the alternative splicing of caspase 9 and Bcl-x in A549 lung adenocarcinoma cells. Dependence on protein phosphatase-1," Journal of Biological Chemistry, vol. 277, no. 15, pp. 12587-12595, 2002.

[62] D. K. Perry, J. Carton, A. K. Shah, F. Meredith, D. J. Uhlinger, and Y. A. Hannun, "Serine palmitoyltransferase regulates de novo ceramide generation during etoposide-induced apoptosis," Journal of Biological Chemistry, vol. 275, no. 12, pp. 9078-9084, 2000.

[63] H. T. Wang, B. J. Maurer, C. P. Patrick, and M. C. Cabot, "N-(4-hydroxyphenyl)retinamide elevates ceramide in neuroblastoma cell lines by coordinate activation of serine palmitoyltransferase and ceramide synthase," Cancer Research, vol. 61, no. 13, pp. 5102-5105, 2001.

[64] J. D. Fishbein, R. T. Dobrowsky, A. Bielawska, S. Garrett, and Y. A. Hannun, "Ceramide-mediated growth inhibition and CAPP are conserved in Saccharomyces cerevisiae," Journal of Biological Chemistry, vol. 268, no. 13, pp. 9255-9261, 1993.

[65] J. Quintans, J. Kilkus, C. L. McShan, A. R. Gottschalk, and G. Dawson, "Ceramide mediates the apoptotic response of WEHI 231 cells to anti- immunoglobulin, corticosteroids and irradiation," Biochemical and Biophysical Research Communications, vol. 202, no. 2, pp. 710-714, 1994. 
[66] A. M. Vacaru, F. G. Tafesse, P. Ternes et al., "Sphingomyelin synthase-related protein SMSr controls ceramide homeostasis in the ER," Journal of Cell Biology, vol. 185, no. 6, pp. 1013 1027, 2009.

[67] S. A. Novgorodov, D. A. Chudakova, B. W. Wheeler et al., "Developmentally regulated ceramide synthase 6 increases mitochondrial $\mathrm{Ca}^{2+}$ loading capacity and promotes apoptosis," Journal of Biological Chemistry, vol. 286, no. 6, pp. 4644 4658, 2011.

[68] L. A. Boven, M. van Meurs, R. G. Boot et al., "Gaucher cells demonstrate a distinct macrophage phenotype and resemble alternatively activated macrophages," American Journal of Clinical Pathology, vol. 122, no. 3, pp. 359-369, 2004.

[69] A. H. Futerman, J. L. Sussman, M. Horowitz, I. Silman, and A. Zimran, "New directions in the treatment of Gaucher disease," Trends in Pharmacological Sciences, vol. 25, no. 3, pp. 147-151, 2004.

[70] P. Ashton-Prolla, B. Tong, J. Shabbeer, K. H. Astrin, C. M. Eng, and R. J. Desnick, "Fabry disease: twenty-two novel mutations in the $\alpha$-galactosidase a gene and genotype/phenotype correlations in severely and mildly affected hemizygotes and heterozygotes," Journal of Investigative Medicine, vol. 48, no. 4, pp. 227-235, 2000.

[71] Y. Kacher and A. H. Futerman, "Genetic diseases of sphingolipid metabolism: pathological mechanisms and therapeutic options," FEBS Letters, vol. 580, no. 23, pp. 5510-5517, 2006.

[72] R. Myerowitz, D. Lawson, H. Mizukami, Y. Mi, C. J. Tifft, and R. L. Proia, "Molecular pathophysiology in Tay-Sachs and Sandhoff diseases as revealed by gene expression profiling," Human Molecular Genetics, vol. 11, no. 11, pp. 1343-1350, 2002.

[73] G. M. Petersen, J. I. Rotter, and R. M. Cantor, "The TaySachs disease gene in North American Jewish populations: geographic variations and origin," American Journal of $\mathrm{Hu}$ man Genetics, vol. 35, no. 6, pp. 1258-1269, 1983.

[74] T. Yamashita, Y. P. Wu, R. Sandhoff et al., "Interruption of ganglioside synthesis produces central nervous system degeneration and altered axon-glial interactions," Proceedings of the National Academy of Sciences of the United States of America, vol. 102, no. 8, pp. 2725-2730, 2005.

[75] T. Yamashita, R. Wada, T. Sasaki et al., "A vital role for glycosphingolipid synthesis during development and differentiation," Proceedings of the National Academy of Sciences of the United States of America, vol. 96, no. 16, pp. 9142-9147, 1999.

[76] R. O. Brady, J. N. Kanfer, M. B. Mock, and D. S. Fredrickson, "The metabolism of sphingomyelin. II. Evidence of an enzymatic deficiency in Niemann-Pick diseae," Proceedings of the National Academy of Sciences of the United States of America, vol. 55, no. 2, pp. 366-369, 1966.

[77] T. Kolter and K. Sandhoff, "Sphingolipid metabolism diseases," Biochimica et Biophysica Acta, vol. 1758, no. 12, pp. 2057-2079, 2006.

[78] J. L. Dawkins, D. J. Hulme, S. B. Brahmbhatt, M. AuerGrumbach, and G. A. Nicholson, "Mutations in SPTLC1, encoding serine palmitoyltransferase, long chain base subunit1, cause hereditary sensory neuropathy type I," Nature Genetics, vol. 27, no. 3, pp. 309-312, 2001.

[79] K. Bejaoui, C. Wu, M. D. Scheffler et al., "SPTLC1 is mutated in hereditary sensory neuropathy, type 1," Nature Genetics, vol. 27, no. 3, pp. 261-262, 2001.

[80] K. Bejaoui, Y. Uchida, S. Yasuda et al., "Hereditary sensory neuropathy type 1 mutations confer dominant negative effects on serine palmitoyltransferase, critical for sphingolipid synthesis," Journal of Clinical Investigation, vol. 110, no. 9, pp. 1301-1308, 2002.

[81] A. Rothier et al., "Mutations in the SPTLC2 subunit of serine pamitoyltransferase cause heredity sensory and automatic neuropathy type 1," American Journal of Human Genetics, vol. 87, pp. 513-522, 2010.

[82] K. Gable, S. D. Gupta, G. Han, S. Niranjanakumari, J. M. Harmon, and T. M. Dunn, "A disease-causing mutation in the active site of serine palmitoyltransferase causes catalytic promiscuity," Journal of Biological Chemistry, vol. 285, no. 30, pp. 22846-22852, 2010.

[83] N. J. Haughey, V. V. Bandaru, M. Bae, and M. P. Mattson, "Roles for dysfunctional sphingolipid metabolism in Alzheimer's disease neuropathogenesis," Biochimica et Biophysica Acta, vol. 1801, no. 8, pp. 878-886, 2010.

[84] A. Jana and K. Pahan, "Fibrillar amyloid- $\beta$-activated human astroglia kill primary human neurons via neutral sphingomyelinase: implications for Alzheimer's disease," Journal of Neuroscience, vol. 30, no. 38, pp. 12676-12689, 2010.

[85] M. O. W. Grimm, S. Grsgen, T. L. Rothhaar et al., "Intracellular APP domain regulates serine-palmitoyl-CoA transferase expression and is affected in alzheimer's disease," International Journal of Alzheimer's Disease, vol. 2011, Article ID 695413, 2011.

[86] C. M. Kusminski, S. Shetty, L. Orci, R. H. Unger, and P. E. Scherer, "Diabetes and apoptosis: lipotoxicity," Apoptosis, vol. 14, no. 12, pp. 1484-1495, 2009.

[87] X. C. Jiang, C. Yeang, Z. Li et al., "Sphingomyelin biosynthesis: its impact on lipid metabolism and atherosclerosis," Clinical Lipidology, vol. 4, no. 5, pp. 595-609, 2009.

[88] M. Fuller, "Sphingolipids: the nexus between Gaucher disease and insulin resistance," Lipids in Health and Disease, vol. 9, article 113, 2010.

[89] W. C. Huang, C.-L. Chen, Y.-S. Lin et al., "Apoptotic sphingolipid ceramide in cancer therapy," Journal of Lipids, vol. 2011, Article ID 565316, 15 pages, 2011.

[90] P. P. Ruvolo, "Ceramide regulates cellular homeostasis via diverse stress signaling pathways," Leukemia, vol. 15, no. 8 , pp. 1153-1160, 2001.

[91] A.-M. Domijan and A. Y. Abramov, "Fumonisin B1 inhibits mitochondrial respiration and deregulates calcium homeostasis-implication to mechanism of cell toxicity," International Journal of Biochemistry and Cell Biology, vol. 43, no. 6, pp. 897-904, 2011.

[92] K. Romero Rosales, G. Singh, K. Wu et al., "Sphingolipidbased drugs selectively kill cancer cells by down-regulating nutrient transporter proteins," Biochemical Journal, vol. 439, no. 2, pp. 299-311, 2011.

[93] C. M. Koeller and N. Heise, "The sphingolipid biosynthetic pathway is a potential target for chemotherapy against chagas disease," Enzyme Research, vol. 2011, Article ID 648159, 13 pages, 2011.

[94] N. Awazu, K. Ikai, J. Yamamoto et al., "Structures and antifungal activities of new aureobasidins," Journal of Antibiotics, vol. 48, no. 6, pp. 525-527, 1995.

[95] K. Ikai, K. Takesako, K. Shiomi et al., "Structure of aureobasidin A," Journal of Antibiotics, vol. 44, no. 9, pp. 925-933, 1991.

[96] S. M. Mandala, R. A. Thornton, M. Rosenbach et al., "Khafrefungin, a novel inhibitor of sphingolipid synthesis," Journal of Biological Chemistry, vol. 272, no. 51, pp. 32709-32714, 1997.

[97] S. M. Mandala, R. A. Thornton, J. Milligan et al., "Rustmicin, a potent antifungal agent, inhibits sphingolipid synthesis 
at inositol phosphoceramide synthase," Journal of Biological Chemistry, vol. 273, no. 24, pp. 14942-14949, 1998.

[98] G. H. Harris, A. Shafiee, M. A. Cabello et al., "Inhibition of fungal sphingolipid biosynthesis by rustmicin, galbonolide B and their new 21-hydroxy analogs," Journal of Antibiotics, vol. 51, no. 9, pp. 837-844, 1998.

[99] M. L. Salto, L. E. Bertello, M. Vieira, R. Docampo, S. N. J. Moreno, and R. M. De Lederkremer, "Formation and remodeling of inositolphosphoceramide during differentiation of Trypanosoma cruzi from trypomastigote to amastigote," Eukaryotic Cell, vol. 2, no. 4, pp. 756-768, 2003.

[100] A. K. Tanaka, V. B. Valero, H. K. Takahashi, and A. H. Straus, "Inhibition of Leishmania (Leishmania) amazonensis growth and infectivity by aureobasidin A," Journal of Antimicrobial Chemotherapy, vol. 59, no. 3, pp. 487-492, 2007.

[101] J. M. Figueiredo, W. B. Dias, L. Mendonça-Previato, J. O. Previato, and N. Heise, "Characterization of the inositol phosphorylceramide synthase activity from Trypanosoma cruzi," Biochemical Journal, vol. 387, no. 2, pp. 519-529, 2005.

[102] E. S. Sevova, M. A. Goren, K. J. Schwartz et al., "Cell-free synthesis and functional characterization of sphingolipid synthases from parasitic trypanosomatid protozoa," Journal of Biological Chemistry, vol. 285, no. 27, pp. 20580-20587, 2010.

[103] Y. Sugimoto, H. Sakoh, and K. Yamada, "IPC synthase as a useful target for antifungal drugs," Current Drug Targets, vol. 4, no. 4, pp. 311-322, 2004.

[104] P. A. Aeed, C. L. Young, M. M. Nagiec, and Å. P. Elhammer, "Inhibition of inositol phosphorylceramide synthase by the cyclic peptide aureobasidin A," Antimicrobial Agents and Chemotherapy, vol. 53, no. 2, pp. 496-504, 2009.

[105] J. G. Mina, J. A. Mosely, H. Z. Ali, P. W. Denny, and P. G. Steel, "Exploring Leishmania major Inositol Phosphorylceramide Synthase (LmjIPCS): Insights into the ceramide binding domain," Organic and Biomolecular Chemistry, vol. 9, no. 6, pp. 1823-1830, 2011.

[106] O. Zhang, M. C. Wilson, W. Xu et al., "Degradation of host sphingomyelin is essential for Leishmania virulence," Plos Pathogens, vol. 5, no. 12, Article ID e1000692, 2009.

[107] W. Xu, L. Xin, L. Soong, and K. Zhang, "Sphingolipid degradation by Leishmania major is required for its resistance to acidic $\mathrm{pH}$ in the mammalian host," Infection and Immunity, vol. 79, no. 8, pp. 3377-3387, 2011.

[108] M. C. Fernandes, M. Cortez, A. R. Flannery, C. Tam, R. A. Mortara, and N. W. Andrews, "Trypanosoma cruzi subverts the sphingomyelinase-mediated plasma membrane repair pathway for cell invasion," Journal of Experimental Medicine, vol. 208, no. 5, pp. 909-921, 2011.

[109] K. Tatematsu, Y. Tanaka, M. Sugiyama, M. Sudoh, and M. Mizokami, "Host sphingolipid biosynthesis is a promising therapeutic target for the inhibition of hepatitis B virus replication," Journal of Medical Virology, vol. 83, no. 4, pp. 587-593, 2011.

[110] S. D. Spassieva, T. D. Mullen, D. M. Townsend, and L. M. Obeid, "Disruption of ceramide synthesis by CerS2 downregulation leads to autophagy and the unfolded protein response," Biochemical Journal, vol. 424, no. 2, pp. 273-283, 2009. 

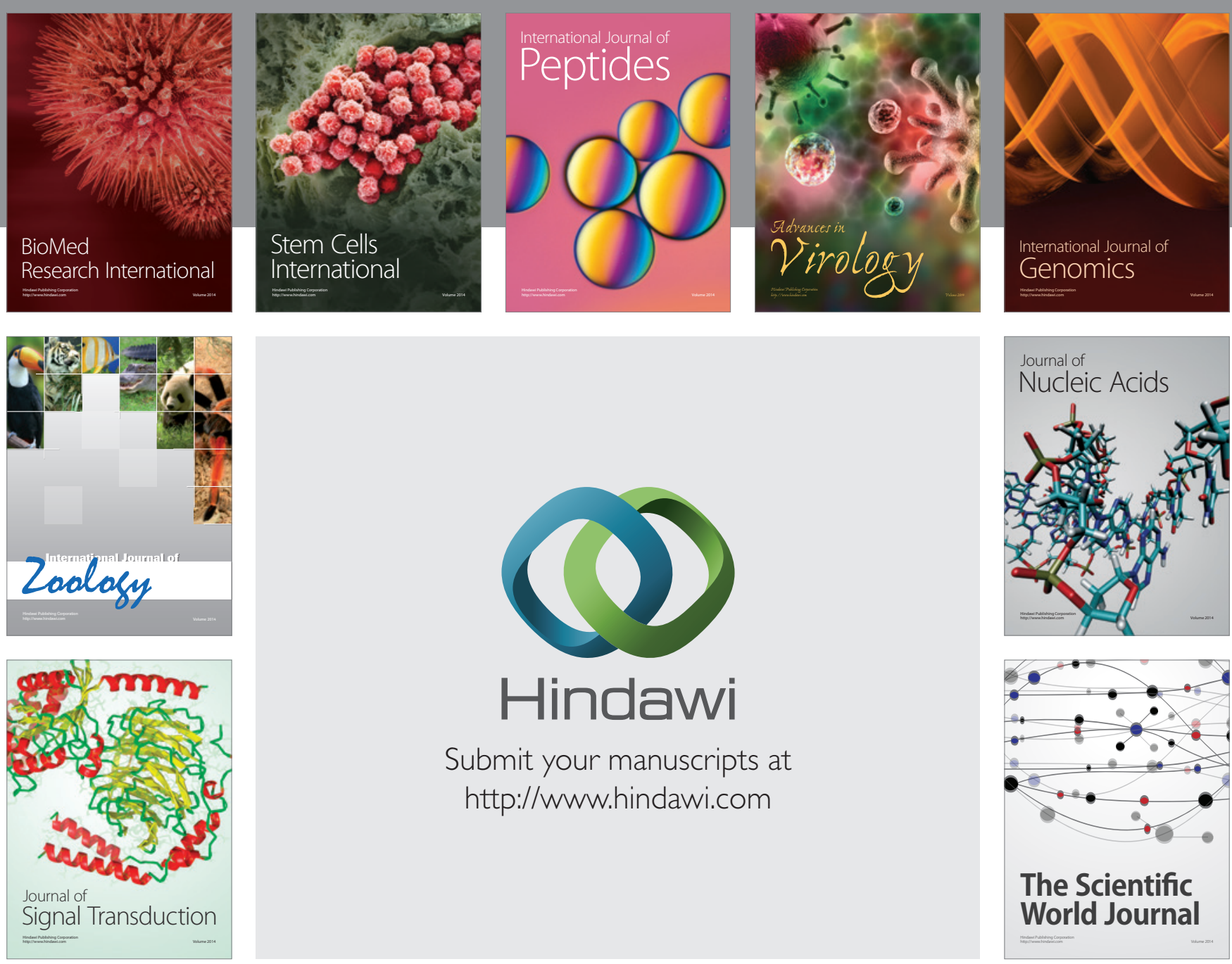

Submit your manuscripts at

http://www.hindawi.com
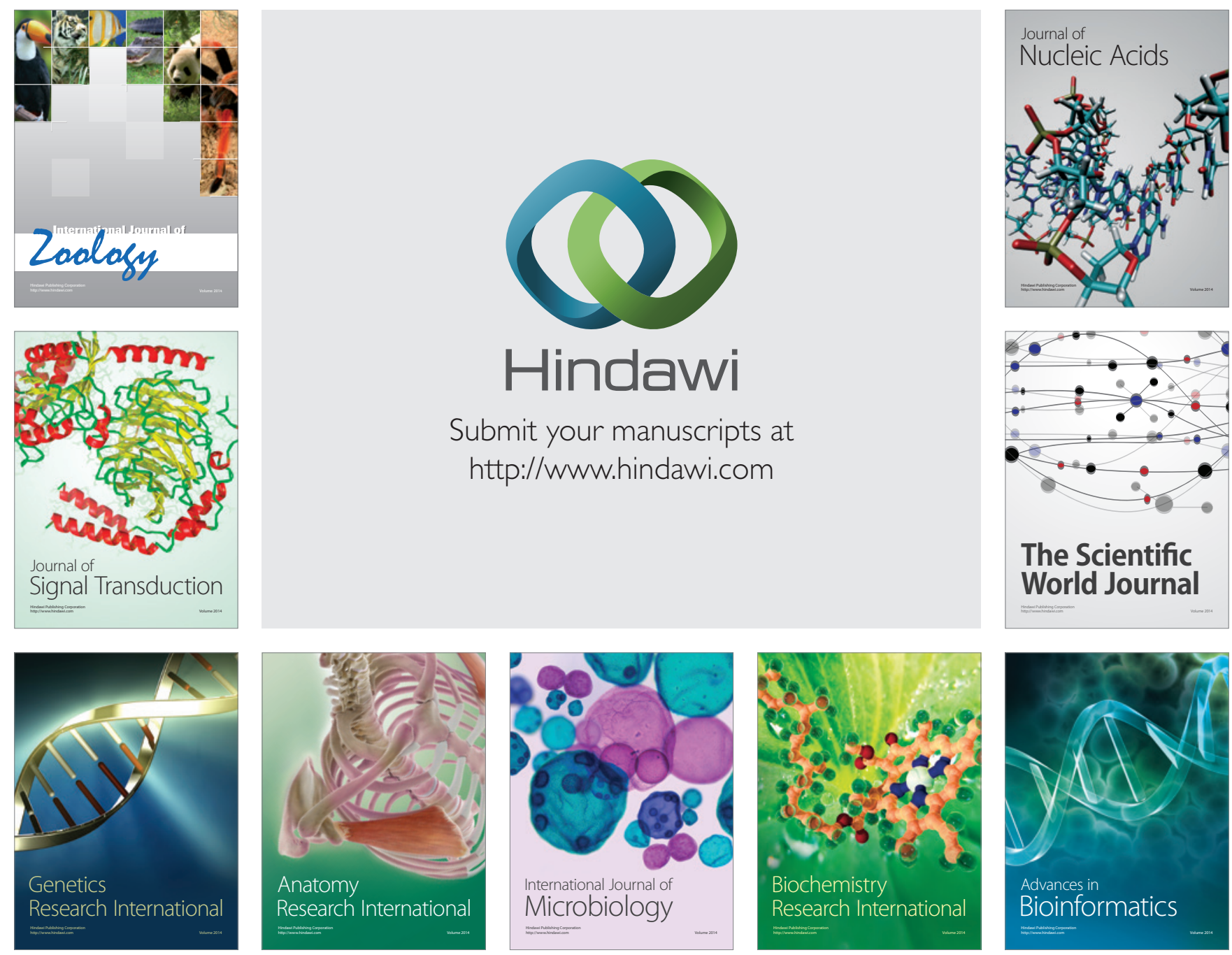

The Scientific World Journal
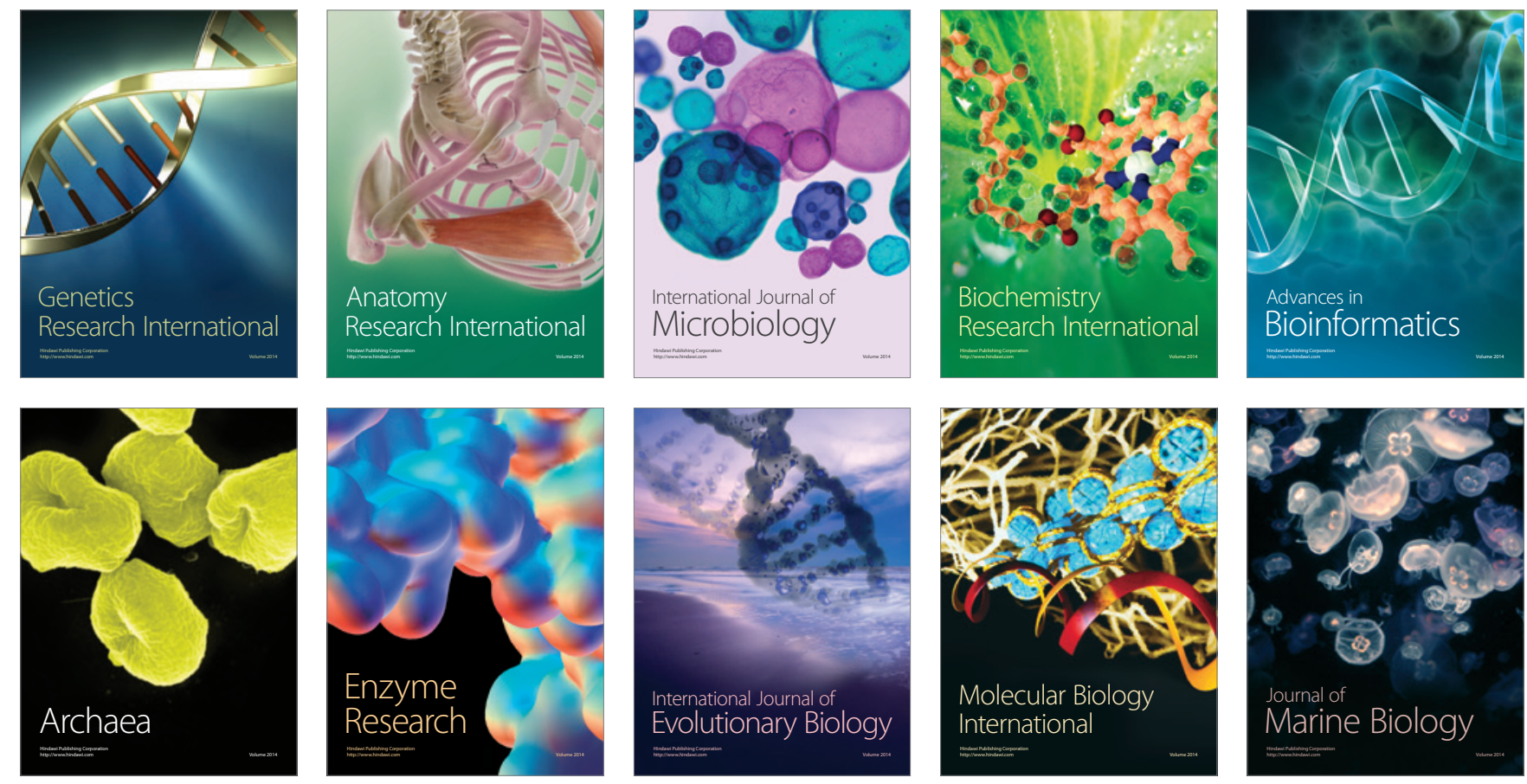